UDC $614.38(470)$

DOI: 10.21668/health.risk/2020.1.09.eng

\title{
ON EPIDEMIOLOGIC RISKS, THEIR CATEGORIES AND PREDICTORS IN SANITARY-EPIDEMIOLOGIC (BIOLOGICAL) EMERGENCY SITUATIONS
}

\author{
S.K. Udovichenko ${ }^{1}$, V.P. Toporkov ${ }^{2}$ \\ ${ }^{1}$ Volgograd Scientific Research Anti-Plague Institute, 7 Golubinskata Str., Volgograd, 400131, Russian Federation \\ ${ }^{2}$ «Microbe» Russian Scientific Research Anti-Plague Institute, 46 Universitetskaya Str., Saratov, 410005, \\ Russian Federation
}

Nowadays sanitary-epidemiologic (biological) emergency situations can be overlooked, especially at an initial stage in epidemiologic risks realization and the consequent development of epidemic process. A clear example here is how Ebola epidemics started in the Western Africa (2013-2016).

Our research goal was to obtain actual data on any existing crucial combinations of epidemiologic risk categories and predictors as emergency situations precursors.

Our basic research procedure was a complex epidemiologic one. Our work was based on analyzing official data provided by the World Health Organization, WHO Regional Office for Africa, as well as taken from multiple research works and monographs.

We analyzed two epidemics caused by infectious agents belonging to the $1^{\text {st }}$ pathogenicity group, Ebola epidemics in the Western Africa (2013-2016) and pneumonic plague epidemic in Madagascar (2017). Both those epidemics were characterized with such potential emergency situations properties fixed in the International Health Regulations (2005) as unexpectedness, unusualness, and gravity. We showed that each epidemic had its own crucial combination of epidemiologic risk categories and their functionality and predictors that were emergency situations precursors. Those combinations occurred just at the very beginning of the epidemics development, after epidemiologic risks had manifested and an epidemic process started to develop intensively and extensively. We assume that should a data base with data on such combinations be created, monitoring over them and targeted activities aimed at their elimination will allow enhancing a preventive potential of the International Health Regulations (2005) as regards emergency situations.

Key words: sanitary-epidemiological (biological) emergency situation, epidemiologic risk, epidemiologic risk categories, predictors, epidemic process, International Health Regulations (2005), Ebola virus disease epidemic in West Africa (2013-2016), pneumonic plague epidemic on Madagascar (2017), prevention and control of emergency situations.

Eliminating Ebola epidemics in the Health Regulations (IHR, 2005) in WHO Western Africa in 2013-2016 was a rather member states. The above-mentioned lessons painful experience and lessons learnt from it were critically analyzed and assessed by the WHO experts; these assessments can be found in official reports issued after several sessions of the World Health Assembly, mostly the 68th (A68/22 - 2015) and the 69th (A69/21 - 2016). It became obvious that WHO activities aimed at managing emergency situations (ES) in public healthcare needed reforming; it was also necessary to adopt the WHO program on ES in public healthcare within streamlining and enhancing implementation of the International as well as results obtained via scientific research on the matter [1] revealed that an epidemic onset in Guinea Republic was actually missed; the epidemic was registered by public healthcare officials on the local, regional, national and international levels when it was already too late; its subsequent etiological verification was too protracted. All the above mentioned resulted in steady growth in the epidemic process spreading into large settlements, cities, and other countries as well; overdue announcement by the WHO that there was an interna-

(C) Udovichenko S.K., Toporkov V.P., 2020

Svetlana K. Udovichenko - Candidate of Medical Sciences acting as the Leading Researcher at the Laboratory for Epidemiologic Analysis and Anti-Epidemic Provision (e-mail: vari2@sprint-v.com.ru; tel.: +7 (8442) 39-33-36; ORCID: https://orcid.org/0000-0001-8682-1536).

Vladimir P. Toporkov - Doctor of Medical Sciences, Professor, the Chief Researcher at the Laboratory for Epidemiologic Analysis and Prediction (e-mail: rusrapi@microbe.ru; tel.: +7 (845) 226-21-31; ORCID: https://orcid.org/0000-0001-9512-7415). 
tionally significant ES in public healthcare; the epidemic becoming a priority threat to the national securities of countries in the grip of it and the security of the overall international society as well.

Bearing all this in mind, it calls for developing a set of activities aimed at early detection and, consequently, timely prevention of such ES. At present such a set can be most easily developed basing on creating a methodological base in addition to methodical instruments for ES verification outlined in the IHR (2005). This methodical base would allow detecting and monitoring over the earliest and the most dangerous combinations of epidemiologic risk categories and predictors that were "catalysts" for an epidemic process development.

Initial realization of an epidemiologic risk is known to underlie any epidemic event (a sporadic infectious disease case, an outbreak, an epidemic, a pandemic). An epidemiologic risk is a potential possibility that an epidemiologic situation will deteriorate. Russian epidemiologists V.D. Belyakov and B.L. Cherkasskiy differentiated an epidemiologic risk into 4 categories it was made up of; they were "risk territory", "risk factors", "risk period", and "risk groups" $[2,3]$.

"Risk territory" is a territory where an infectious agent occurs and persists; there are landscape-ecological and natural-biocoenotic conditions necessary for its circulation; people can get infected there, and an epidemic process can then develop. "Risk factors" are animated and non-animated nature objects that contain an infectious agent and a person gets infected when contacting them; it results in a threat that an epidemic process will develop. "Risk period" is a period during which there is a longterm or seasonal growth in a quantity of an infectious agent in risk factors and people are most likely to get infected and an epidemic process is most likely to develop. "Risk groups" are population who are (permanently or temporarily) on a risk territory including an epidemic focus and who are, due to various circumstances, most likely to contact risk factors, infected people, infection sources, and infectious agents.

Nowadays when epidemiologic diagnostics is accomplished in real life conditions, an epidemiologic risk is assessed taking into account all categories it is made of; any targeted (risk-oriented) sanitary-preventive (anti-epidemic) activities or activities within epidemiologic control, to be exact, should be aimed at minimizing these categories. Thus, a complex assessment of an epidemiologic risk is accomplished when it is necessary to provide sanitary-epidemiologic welfare of mass events with international participation and to prevent any ES; such assessment should be accomplished as per all the components of an epidemiologic risk without any differentiation of their functional significance and for any infectious disease that can be potentially dangerous in terms of ES occurrence. When calculating potential epidemic threats related to a mass event with international participation, one should take into account both external threats (actually existing and additionally imported) and internal ones ${ }^{1}$.

Naturally, probability and fast realization of an epidemiologic risk as a whole or its separate categories to a great extent depend on biological properties of infectious agents and them belonging to I-II pathogenicity groups; their ability to induce an epidemic process with aggravated clinical course and high lethality; extensive and intensive manifestation; and their overall ability to disseminatingly circulate in nature and a human society accordingly on the ecosystem and socio-ecosystem levels in an epidemic process [4]. But still, bearing in mind the experience gained in eliminating Ebola epidemic in the Western Africa, we can assume that significant epidemic events, like epidemic or pandemics, that is, internationally significant sanitary-epidemiologic (biological) ES occur and develop provided that there are extraordinary combina-

\footnotetext{
${ }^{1}$ M.A. Patyashina Scientific grounds for providing sanitary-epidemiologic welfare of international mass events and their implementation exemplified by the XXVII Summer Universiade in Kazan: doctoral thesis. Saratov, 2015, 337 p.
} 
tions of functional peculiarities related to separate categories included into an overall epidemiologic risk and specific predictors that are "catalysts" for an epidemic process development over time and space.

As for predictors that are able to result in faster ES occurrence, there are such analogues to them in epidemiology as social and natural factors that activate an epidemic process ${ }^{2}$ and, consequently, increase a probability that it will grow significantly enough to become an ES. Among them there are geophysical phenomena or natural disasters (earthquakes, floods, or droughts); biological events (mass spread of small rodents on vast territories and those rodents being carriers of dangerous infectious agents). There are also social factors (predictors) such as ethnical military conflicts, high migration activity of population, intense traffic flows between territories, etc. A principally significant predictor is relevant development and structural and functional organization of epidemiologic monitoring, epidemiologic surveillance, and epidemiologic control. It means that there are efficient organizational, epidemiologic and diagnostic (clinical-epidemiologic diagnostics and etiological verification), medical, preventive, and anti-epidemic activities and measures accomplished and taken in case of well-known infectious diseases. It is also necessary to have an algorithm for fast creation of such a set of activities and measures to control new emerging nosology forms as they constantly appear all over the world (predominantly in Asia and Africa) and to meet the requirements fixed in the IHR (2005) and developed basing on accomplishing response activities in case of such epidemic events. In particular, the List No.1 in the Appendix 2 of the IHR (2005) contains a model that describes a new infectious disease with maximum possible destructive potential that threatens the whole international society. This new infectious disease is flu of a new sub-type which is unknown at the moment but predicted by the WHO to cause pandemic as it is expected to have high lethality typical for A (H5NI) bird flu and to be easily transferred from a person to person as it is the case with seasonal flu.

All the hypotheses regarding occurrence of infectious agents with such combinations of biological properties that make them a potential threat of an ES, relevant clinical and epidemiological signs of infectious diseases, epidemiologic risk categories and predictors (ES precursors) are to be initially examined on examples of epidemics that have occurred over recent years. It is advisable to choose epidemics that were caused by infectious agents belonging to I pathogenicity group ${ }^{3}$ and had such properties as unexpectedness, unusualness, and gravity; these properties were, according to the IHR (2005), typical ES-preceding signs and epidemics that had them could cause a potential threat of an ES on national and international levels. Examples of such epidemics are an Ebola epidemic in the Western Africa (2013-2016) and a wide-scale pneumonic plague epidemic in Madagascar in 2017.

Our research goal was to obtain actual data on critical combinations of epidemiologic risk categories and predictors as precursors of epidemic process development and occurrence of a sanitary-epidemiologic (biological) ES.

Data and methods. We applied a complex epidemiologic procedure in the present work. Our information resources to obtain data for analysis were official reports by the WHO, WHO Regional Office for Africa, scientific papers and monographs. The text was designed on a PC with installed Microsoft Windows 7 Professional and Microsoft Office 2017.

Results and discussion. The Ebola epidemic in the Western Africa is of special importance for assessing combinations of epidemiologic risk categories and predictors. It occurred in 2013-2016 and predominantly spread in three countries, namely Guinea, Liberia, and Sierra Leone. The epidemic was defined by the WHO as a grave large-scale internationally sig-

\footnotetext{
${ }^{2}$ Guide on infectious diseases epidemiology. In: N.I. Briko, G.G. Onishchenko, V.I. Pokrovskiy eds. Moscow, "Medical Information Agency" Publ., 2019, vol. 1, 2019, 880 p.

${ }^{3}$ SR 1.3.3118-13. Safety of work with microorganisms belonging to the I-II pathogenicity (hazard) groups issued on November 28, 2013 No, 64. Moscow: The Rospotrebnadzor's Federal Center for Hygiene and Epidemiology Publ., 2014, 195 p.
} 
nificant ES in public healthcare. Scientific works treated it as an internationally significant ES in the sphere of biological safety. 28,616 people got infected and fell sick, 11,310 of them died (lethality was equal to $39.5 \%$ ) [5]. Such a great number of sick people registered in such a short period of time (mostly in 2014-2015) is incommensurable with much smaller numbers of infected and sick people detected in Africa over comparably long-term periods of time.

Prior to the epidemic in the Western Africa, Ebola outbreaks were registered mostly in the Central Africa (the Democratic Republic of Congo, Gabon, and Congo), and the Eastern Africa (Southern Sudan and Uganda) [6]. Since Ebola was first described in 1976 and up to 2012 there were 24 outbreaks and single disease cases, the overall number of sick people amounted to $2,433,1,581$ out of them died (lethality was equal to $65 \%$ ). In 2014, 2017, 2018-2019 there were 4 Ebola outbreaks in the Democratic Republic of Congo, overall number of sick people amounted to 3,049 and 2,050 out of them died (WHO data on September 03, 2019).

Ebola epidemic process in the Western Africa has already been analyzed with the focus on step-by-step development of an ES in the sphere of biological safety and efficiency of methodical tools provided in the IHR (2005) for early detection, timely communication, and taking relevant measures aimed at eliminating the said epidemic, especially at initial stages in its development. It seems logical to examine combinations of epidemiologic risk categories and predictors and their dynamics during the said epidemic as an ES as per 4 stages in its development that were previously identified.

The $1^{\text {st }}$ stage was characterized with local outbreaks in a zone where initial contagion occurred and epidemiologic risk was realized in Guinea. As per its phenomenological characteristics, it was a typical natural-focus infection starting with the first infected person (it was a two-year old boy who fell sick on December 02, 2013 and died on December 06, 2013 in Meliandu village in Gekedu pre- fecture in south-eastern Guinea). Ebola virus is thought to circulate in nature in Guinea thanks to bats, and small predator rodents belonging to viverrids family can be an interlink in a mechanism of infection transfer to people.

An initial outbreak was limited to rural population and forest zones [7]. It was characterized with grave clinical course of the disease, high lethality, and high frequency of anthropogenic transfer of the infectious agent, medical personnel being involved into the epidemic process, and the infection being a hospital-acquired one. Such features are a sufficient reason for verifying this epidemiologic situation with IHR (2005) tools as unexpected, unusual, grave, and potentially hazardous in terms of ES occurrence. But any signs hinting at a probable future ES were not verified due to the outbreak being local and occurring in remote places; therefore, its social and economic significance was practically imperceptible at that stage. Partially it was due to national and international public healthcare experts both in the Western Africa and the African continent as a whole traditionally paying the greatest attention to the most significant and gravest issues related to diseases with serious social and economic consequences, such as malaria, HIV/AIDS, tuberculosis, B type hepatitis, etc.

Only on March 10, 2014 hospitals and medical institutions located in Gekedu and Macenta settlements passed data on the outbreak to the Guinea Ministry for Public Healthcare and Hygiene; on March 12 the information was given to the local office of "Doctors without Borders" international nongovernmental organization that had been operating in Guinea since 2010 within a project aimed at fighting against malaria [8]. Practically at the $1^{\text {st }}$ stage in the outbreak there were certain predictors that allowed forecasting it would most likely develop into an epidemic and then ES. They were as follows:

- a moment an outbreak started in forest zones and rural areas was totally missed and it made for the epidemic process spread into large settlements and cities;

- changes occurring in Ebola syndromes such as a substantial decrease in frequency of 
hemorrhagic fever syndrome and an increase in frequency of diarrhea symptoms in the clinical picture of the diseases in the Western Africa in comparison to the Central Africa;

- too much time required for clinical and epidemiological diagnostics and etiological verification of the disease (first cases were communicated in January 2014) due to changes in syndromes;

- public healthcare experts not being ready to verify ES signs fixed in the IHR (2005);

- national and international public healthcare institutions being predominantly preoccupied with finding solutions to epidemiological problems existing in Africa that were urgent, large-scale and resource-consuming and not being ready for a probable Ebola outbreak in the Western Africa;

- underestimation of landscape-ecological and natural biocoenotic complexes existing in Guinea that were favorable for Ebola spread among animals and occurrence of all epidemiologic risk categories taking into account results of seroconversion among people which indicated Ebola infectious agent might have circulated in Guinea and other Western African countries in the past [9-11].

The second stage was characterized with the disease spreading from its initial epidemic focus into large cities and Conakry, the capital of Guinea, where Guinea international airport was located and, consequently, there was a risk that the disease could spread internationally. The basic predictor at the stage was a delay by the WHO in declaring there was an ES; the declaration was made 4 months after the outbreak started even though there were practically all signs fixed in the IHR (2005) and, therefore, such a delay is hardly explainable. It made it impossible to adequately mobilize all sources and efforts to fight against progressive development of the epidemic process in cities in Guinea and first disease cases in Liberia.

At the $3^{\text {rd }}$ stage the disease spread into neighboring countries (Liberia and Sierra Leone) and there was an actual large-scale ES in public healthcare which remained undeclared by the WHO but already had international significance due to integral effects pro- duced by predictors at the $1^{\text {st }}$ and $2^{\text {nd }}$ stages. "Risk groups" category became more and more significant at this stage, due to ethnic peculiarities, rumors, and conjectures regarding Ebola outbreak that had never previously occurred in cities and it made for faster infection spread, and to negative attitudes towards antiepidemic activities, especially when deceased patients were buried [12].

At the $4^{\text {th }}$ stage morbidity grew explosively in Guinea, Liberia, and Sierra Leone, spread into other countries on the continent (Nigeria, Senegal, and Mali) and beyond it (European countries and the USA). The predictor at the stage was late declaration by the WHO that the Ebola epidemic in the Western Africa was an internationally significant ES in public healthcare ( 8 months after the epidemic started), when the epidemiological situation reached a critical point next to actual spread of the disease beyond any control. We should also mention such a background predictor as insufficient range and efficiency of medications for treating and preventing Ebola. At this stage "risk groups" category remained the most significant one; it was sue to population who were exposed to the greatest risk to be infected and fall sick not willing to come to terms with the epidemic occurrence; people didn't want to cooperate when anti-epidemic activities were performed and actually tried to prevent them and fight against medical personnel who took enormous efforts to eliminate Ebola and prevent its spread [13-14].

Therefore, at the $4^{\text {th }}$ stage in the Ebola epidemic in the Western Africa that was an internationally significant sanitary-epidemiological (biological) ES there occurred the most critical complex of biological properties that the infectious agent had (viral nature and I pathogenicity group), epidemiologic risk categories, and predictors; it is hardly possible to theoretically imagine a more critical complex in terms of threats to global security and to see how these threats find their realization in real life conditions.

We analyzed one more epidemic event; it was the pneumonic plague outbreak in Madagascar in 2017. It started on August 23, 2017 
and by December 12, 2017 there were 2,529 registered disease cases, most of them $(1,945$ or $77 \%$ ) being pneumonic plague cases. Pneumonic plague was detected in 57 districts in the country out of total $114(50 \%)$, including non-endemic [15]. All the above data indicate there was a pneumonic plague epidemic in 2017 in Madagascar and it occurred when the overall epidemiologic situation in the world in terms of plague was more than favorable ( 3 cases detected in the USA).

The epidemic situation in 2017 in Madagascar had certain unusual features; the most significant one was that an annual number of people who got infected with pneumonic plague and a period of its growth (practically 3.5 months) turned out to be the highest in the world over the last 96 years. A pervious event in the historical periodical series was a pneumonic plague outbreak in Manchuria in 1920-1921 when several tens of thousands people got infected with the disease and died [16].

Today we can consider an epidemic situation that existed in Madagascar prior to the outbreak in 2017 quite "normal". According to the WHO data, from 2000 to 2016 there were 9,869 registered disease cases, their annual average quantity being equal to 580. There were two peaks in morbidity during that period, the $1^{\text {st }}$ one occurred in 2000 when 1,333 people got infected with plague and 63 out of them died; the $2^{\text {nd }}$ one was in 2004, 1,214 disease cases and 98 deaths accordingly. Starting from 2010 Madagascar has been occupying the $1^{\text {st }}$ place in the world as per morbidity with plague [17]. A share of people who have pneumonic plague varies from 2 to $25 \%$ [18]. All the plague cases in Madagascar are caused by Y.pestis strains that belong to the eastern type of biological plague agents. Overall, a rather unfavorable epidemic situation in terms of plague that exists in Madagascar is due to poorly organized and inefficient epidemiologic surveillance. However, the pneumonic plague outbreak that occurred in 2017 can't be explained only by epidemiologic surveillance being insufficient. Obviously, unusual functional peculiarities of epidemiologic risk categories had their own specific role in the epidemic process development.

According to data provided by the WHO Regional Office for Africa and results obtained via operative epidemiologic research, the pneumonic plague outbreak started on August 23, 2017, when a 31-year old man from Tamatave visited Ankazobe area on the Central plateau (a territory which was enzootic as per plague) and then had symptoms of a disease that was similar to malaria. When he went to Tamatave through Antananarivo using public transport (a fixed-run taxi), he suddenly felt himself seriously sick and was taken to Monmoranga district hospital where he died and was buried without any safety precautions taking during the burial. Overall, 31 people contacted him and got infected with the disease; later 4 out of them died. The Madagascar Public Healthcare Ministry officially informed the WHO about the pneumonic plague outbreak on September 13, 2017 after a 47-year old woman had died from a respiratory disease in Soavinandriana Hospital in Antananarivo on September 11, 2017. This secondary case was the reason to start epidemiologic research that allowed detecting the above-mentioned traveler who had been the first to get infected with the disease.

According to the above data, formal stepby-step defects in accomplishing epidemiologic surveillance oriented at timely detection of people who got infected with plague (and not epizooty) were as follows: experts missed the first person who got infected and fell sick with bubonic plague on a territory which was enzootic as per this infection; they neglected bubonic plague complications with the secondary pneumonic type and a death caused by the secondary pneumonic plague in hospital; the first person who died from the disease was buried without any safety precautions; a secondary pneumonic plague case and lethal outcome in hospital in Antananarivo was also missed.

So, defects in epidemiologic surveillance in 2017 resulted in two interrelated pneumonic plague cases and the disease being transferred from an enzootic territory into Antananarivo. 
Those events could be interpreted as being quite usual for Madagascar, especially bearing in mind that the epidemiologic situation as per plague had already been rather unfavorable in 2000-2016.

But still, there were several signs that the pneumonic plague epidemic was large-scale and developed too rapidly; they were a large cluster of registered pneumonic plague cases among people who had contacted the first infected person (secondary cases); occurrence of tertiary cases and avalanche-like growth in pneumonic plague cases without any clear epidemiologic links registered in different parts of the country including areas which were not endemic as per plague and large cities (Antananarivo and Tuamasino).

As for epidemiologic risk categories, "risk groups" category should be the first focus of attention, in particular, the first infected person being unusually active; he was already sick with pneumonic plague and still moved around Antananarivo on his own for a long period of time taking public transport (a fixed-run taxi). Pneumonic plague in people usually tends to have grave clinical course and rapidly occurring lethal outcome. A closed space inside a vehicle and too many passengers getting on and off it created critically significant conditions for absolutely efficient transfer of the plague microbe from the first infected person to all people around him. The situation can be compared to an aerosol chamber where contagion of all live objects placed into it amounts to $100 \%$. It was the "aerosol chamber effect" that allowed creating a critical "pool" of people who fell sick with pneumonic plague; later on it developed into a full-scale epidemic and ES.

The first infected person, being a source of the infection, was simultaneously a risk factor in urban environment that became an anthropogenic risk territory, and all urban population who contacted the infected person became a risk group. When we speak about risk factors in this case, we, above all, should bear in mind the meaning of the word "factor" that is Latin in its origin and means "doing, mak- ing", a driving force of any process, in this case, an epidemic one ${ }^{4}$.

Unusual functional properties of "risk territory" category were determined with the epidemic process spreading into large cities with high population density, developed transport infrastructure, and high migration activity of the population. Usually functionality of a risk territory in Madagascar is restricted to the Central plateau region that is endemic as per plague $[19,20]$ and where multiple cases of predominantly bubonic plague occur among population living in rural areas.

Epidemiologic significance of "risk group" category is due to risk territories extending into urban areas, and as a result urban population being involved into the epidemic process and most pneumonic plague cases being registered exactly among people living in cities. $68 \%$ people who got infected and fell sick with pneumonic plague were detected in Antananarivo. Usual functionality of "risk groups" category in Madagascar is related to rural population that account for more than $80 \%$ diseases cases and predominantly suffer from bubonic plague that is annually aggravated with the secondary pneumonic plague in limited number of cases [21].

Unusual functionality of "risk period" category is due to an earlier start of an epidemic season, on August 23, 2017 (the date when the first person with pneumonic plague was registered) and the plague outbreak occurring in cities already in September; it was probably the reason why the first person with plague wasn't noticed and plague spread into Antananarivo earlier than it was expected. It then led to a rapid spread of the diseases, a lot of people falling sick with pneumonic plague, relatively rapid development of the process into a largescale epidemic and ES. Usual functionality of "risk period" category in Madagascar is related to a seasonal growth in morbidity with plague that normally occurs in October and lasts up to late April.

When speaking about the pneumonic plague epidemic in Madagascar in 2017, we

\footnotetext{
${ }^{4}$ The foreign words dictionary. The 18th edition. Moscow, Russkiy yazyk Publ., 1989, 624 p.
} 
should also remember that there could have been a potential predictor of its extremely unfavorable development. This predictor was plague microbes being resistant to antibiotics that were recommended to be used within the National Anti-plague Program. It had already happened in Madagascar in 1995-1998 [22]. In 2017 all plague microbe strains were sensitive to antibiotics and it was extremely important for establishing epidemic control over the disease.

Conclusion. We took two epidemics caused by infectious agents belonging to I pathogenicity group as our examples; both epidemics had specific features at the moment they started that were fixed in the IHR (2005) and considered to be signs of a future ES; to be exact, the epidemics were unusual, unexpected, and grave. We detected specific functionalities of epidemiologic risk categories and their combinations with predictors that were obvious ES precursors. Obtained data give grounds for more profound research on examples of a wider range of epidemic events in order to reveal the whole variational series of critical combinations of epidemiological risk categories and predictors; to create a relevant database; to monitor necessary data and work out targeted activities that would allow enhancing preventive potential of the IHR (2005) as regards emergency situations.

Funding. The research was not granted any sponsor support.

Conflict of interests. The authors declare there is no any conflict of interest.

\section{References}

1. Onishchenko G.G., Toporkov V.P., Karnaukhov I.G., Udovichenko S.K. Ebola fever epidemic in West Africa as an emergency situation in the sphere of biological safety of international concern. Infektsionnye bolezni: novosti, mneniya, obuchenie, 2016, vol. 14, no. 1, pp. 61-67 (in Russian).

2. Cherkasskii B.L. Risk v epidemiologii [Risk in epidemiology]. Moscow, Prakticheskaya meditsina Publ., 2007, 480 p. (in Russian).

3. Belyakov V.D. Epidemiologicheskii nadzor - osnova sovremennoi organizatsii protivoepidemicheskoi raboty [Epidemiologic surveillance as a basis for organizing up-to-date anti-epidemic activities]. Zhurnal mikrobiologii, epidemiologii i immunobiologii, 1985, vol. 62, no. 5, pp. 53-58 (in Russian).

4. Cherkasskii B.L. Sistema epidemiologicheskogo nadzora kak otrazhenie struktury epidemiccheskogo protsessa [Epidemiologic surveillance as a system reflecting epidemic process structure]. Zhurnal mikrobiologii, epidemiologii i immunobiologii, 1986, no. 11, pp. 74-78 (in Russian).

5. Ebola virus disease: situation report-2016. World Health Organization. Available at: https://apps.who.int/iris/bitstream/handle/10665/208883/ebolasitrep_10Jun2016_eng.pdf; jsessionid= EB2A6146250801E83C5282CBC6491E4F?sequence=1 (15.04.2019).

6. Malvy D., McElroy A.K., De Clerck H., Gunther S., Van Griensven J. Ebola virus disease. Lancet, 2019, vol. 393, no. 10174, pp. 936-948. DOI: 10.1016/S0140-6736 (18) 33132-5

7. Coltart C.E., Lindsey B., Ghinai I., Johnson A.M., Heymann D.L. The Ebola outbreak, 2013-2016: old lessons for new epidemics. Philos Trans R Soc Lond B Biol Sci, 2017, vol. 372, no. 1721, pp. 20160297. DOI: $10.1098 /$ rstb.2016.0297

8. Guinea: Ebola epidemic declared. Medicins sans frontiers, 2014. Available at: http://www. msf.org.uk/article/guinea-ebola-epidemic-declared (20.02.2019).

9. Butenko A.M. Izuchenie tsirkulyatsii arbovirusov v Gvineiskoi Respublike [Studying arboviruses circulation in Guinea Republic]. Meditsinskaya parazitologiya i parazitarnye bolezni, 1996, no. 2, pp. 40-45 (in Russian).

10. Schoepp R.J., Rossi C.A., Khan S.H., Goba A., Fair J.N. Undiagnosed acute viral febrile illnesses, Sierra Leone. Emerg. Infect. Dis., 2014, vol. 20, no. 7, pp. 1176-1182. DOI: 10.3201/eid2007.131265

11. Knobloch J., Albierz E.J., Schmitz H.A. A serological survey on viral hemorrhagic fevers in Liberia. Ann. Virol., 1982, vol. 2, pp. 125-128.

12. Guinea residents «refusing» Ebola treatment. Al Jazeera, 2014. Available at: http: //www.aljazeera.com/news/africa/2014/09/guinea-residents-refusing-ebola-treatment-201492751955453636.html (05.02.2019). 
13. Dixon R. Eight reported dead in attack on Ebola workers in Guinea. Los Angeles Times, 2014. Available at: https://www.latimes.com/world/africa/la-fg-attack-ebola-guinea-outreach-20140918story.html (15.12.2018).

14. Factors that contributed to undetected spread of the Ebola virus and impeded rapid containment. World Health Organization. Available at: https://www.who.int/csr/disease/ebola/one-yearreport/factors/en/ (26.03.2019).

15. Plague outbreak Madagascar: external situation report 14. World Health Organization Regional Office for Africa, Brazzaville, Congo, World Health Organization Publ., 2017. Available at: https://apps.who.int/iris/bitstream/handle/10665/259556/ExPlagueMadagascar04122017.pdf; jsessionid= D67F16A6E023FB02A3DF11F98C8576C0? sequence=1 (12.01.2019).

16. Velichko L.N., Kedrova O.V., Kokushkin A.M. Legochnaya chuma (obzor vspyshek za rubezhom) [Pneumonic plague (outbreaks registered abroad: a review) ]. Problemy osobo opasnykh infektsii, 1998, pp. 3-11 (in Russian).

17. Bertherat E. Plague around the world, 2010-2015. Wkly Epidemiol. Rec, 2016, vol. 8, pp. 89-104.

18. Migliani R., Chanteau S., Rahalison L., Ratsitorahina M., Boutin J.P., Ratsifasoamanana L., Roux J. Epidemiological trends for human plague in Madagascar during the second half of the 20th century: a survey of 20,900 notified cases. Trop. Med. Int Health, 2006, vol. 11, no. 8, pp. 1228-1237.DOI: 10.1111/j.1365-3156.2006.01677.x

19. Brygoo E.R. Epidemiologie de la peste à Madagascar. Arch. Inst. Pasteur Madagascar, 1996, vol. 35, pp. 9-147.

20. Chanteau S. Atlas de la peste a Madagascar. Paris, IRD Editions Publ., 2006, 94 p.

21. Andrianaivoarimanana V., Kreppel K., Elissa N., Duplantier J.M., Carniel E., Rajerison M., Jambou R. Understanding the persistence of plague foci in Madagascar. PLoS Negl Trop Dis, 2013, vol. 7, no. 11, pp. e2382. DOI: 10.1371/journal.pntd.0002382

22. Cabanel N., Bouchier C., Rajerison M., Carniel E. Plasmidmediated doxycycline resistance in a Yersinia pestis strain isolated from a rat. Int J. Antimicrob. Agents, 2018, vol. 51, no. 2, pp. 249-254. DOI: 10.1016/j.ijantimicag.2017.09.015

Udovichenko S.K., Toporkov V.P. On epidemiologic risks, their categories and predictors in sanitary-epidemiologic (biological) emergency situations. Health Risk Analysis, 2020, no. 1, pp. 83-91. DOI: 10.21668/health.risk/2020.1.09.eng

Received: 19.09.2019

Accepted: 03.02.2020

Published: 30.03.2020 